\title{
Arc Root Motion in an Argon-Hydrogen DC Plasma Torch
}

\author{
Heji Huang, Wenxia Pan, and Chengkang Wu
}

\begin{abstract}
Arc root motion on the anode surface of a dc nontransferred plasma torch was observed. Adding hydrogen changes the arc root attachment from a diffused type to a constricted type, and the arc root of $\mathrm{Ar}-\mathrm{H}_{2}$ plasma suddenly jumps from one spot to another irregularly. Images of the arc root motions taken by a high-speed video camera are presented.
\end{abstract}

Index Terms-Arc root motion, $\mathrm{Ar}-\mathrm{H}_{2}$ plasma, dc plasma, high speed video camera, plasma stability.

D IRECT CURRENT (dc) thermal plasmas, created by an electrical discharge between two electrodes, are used in many industrial processes including cutting, welding, selective waste evaporation, and spraying. In a dc plasma torch, the arc must be connected between the anode and the cathode, which means that a small column of the arc (arc root) must reach the anode surface by crossing the cold gas surrounding the plasma column and finally releasing the energy of electrons. The density of such electronic heat flux can be as high as $\sim 10^{11} \mathrm{~W} / \mathrm{m}^{2}$ so the motions of the arc root are very important because such high heat flux is closely related to the anodic erosion; The flux accordingly affects the reproducibility and efficiency of the process. Although a wealth of experimental and modeling work has been performed [1]-[3], it is still hard to directly observe the arc root attachments because the lifetime of the arc root is usually less than $150 \mu \mathrm{s}$, and the intensive light emitted from the arc column prevents us from observing the weakly luminous arc root. In our previous work, a novel approach was adopted to image the arc root behavior using a specially designed copper mirror whose central region of the surface is coated by a boron nitride (BN) film. The $45^{\circ}$ tilted copper mirror was put directly under the plasma torch to reflect the image of the status of the torch into the camera outside of the vacuum chamber. The centrally coated boron nitride film was in the shape of an ellipse and was used to suppress the perturbation from unwanted light emitting from the arc column [4].

Images in this paper were taken with a high-speed video camera (MotionBLITZ Cube36C, Unterschleissheim, Germany) equipped with a Navitar $50 \mathrm{~mm}$ F0.95 TV lens. The camera speed was set at 4270 frames per second, and the exposure time for each frame was set at $100 \mu \mathrm{s}$. The aperture of the lens was

Manuscript received November 30, 2007; revised February 14, 2008. This work was supported by the National Natural Science Foundation of China (10645004, 10575127, 50702064).

The authors are with the Institute of Mechanics, Chinese Academy of Sciences, Beijing 100190, China (e-mail: huang@imech.ac.cn).

Digital Object Identifier 10.1109/TPS.2008.920226
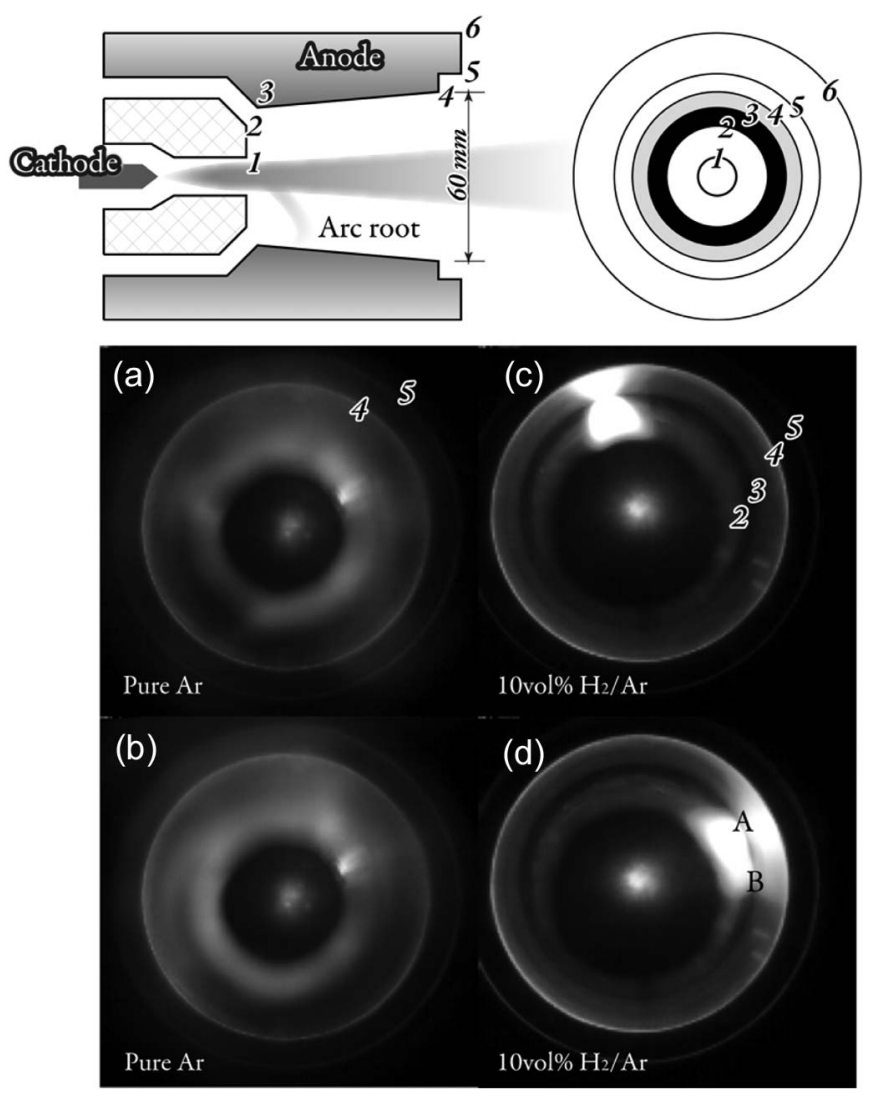

Fig. 1. Configuration of the de nontransferred plasma torch and the images of the arc root attachments on the anode surface of pure argon [(a) and (b)] and $10 \mathrm{vol} \% \mathrm{H}_{2} /$ Ar plasmas [(c) and (d)] at different times.

kept constant at 2. The plasma was generated at arc current of $80 \mathrm{~A}$. Pure argon and $10 \% \mathrm{vol} \mathrm{H}_{2} / \mathrm{Ar}$ with total gas flow rates of $17.6 \mathrm{slm}$ were used as plasma gas, respectively.

Fig. 1 shows the configuration of the dc plasma torch and the images of the arc root attachments on the anode surface. Because the $45^{\circ}$ tilted copper mirror reflects the upward view of the inner parts of the plasma torch, the images attained show many circles, which corresponds to the different edges of the torch (marked by numbers 1-6 in Fig. 1). The anode surface is between circles 3 and 4 . The central dark spots in the photos are images of the coated boron nitride film. Because the thin BN film cannot fully scatter the strong light of the plasma column, there is still a relatively bright spot in the very center.

Fig. 1(a) and (b) show the diffused-type arc root attachment of pure Ar plasma at different times where no concentration of the arc root is available. Adding hydrogen changes the type of 
the arc root from a diffused one to a constricted one, which is thought to be caused by a thicker cold boundary layer (CBL) at the anode surface when $\mathrm{H}_{2}$ is added. Most of the frames attained for $\mathrm{Ar}-\mathrm{H}_{2}$ plasma show similar images as illustrated in Fig. 1(c); the attachment spot is relatively small, which means that a high density of electron energy exists. Note that only the inner bright region represents the arc root; the outer one is the image of the arc root reflected by the shining anode surface. Although the width of the arc roots remains almost the same at different times, e.g., in consecutive frames, the position of the attachment varies irregularly, indicating the sudden-jump behavior of the arc root. Fig. 1(d) captures just such a sudden jump when the arc root moves from spot B to spot A. A much wider attachment can be observed in this case, which means that within the exposure time, the arc root moves over a wide area. The segment of the path is around $15 \mathrm{~mm}$, indicating that the speed of the sudden jump was at least $150 \mathrm{~m} / \mathrm{s}$, since the exposure time of the image is $100 \mu \mathrm{s}$. Because the central part of the arc root attachment in Fig. 1(d) is weaker than the two ends, it may suggest that the real jumping speed of the arc root can be much larger.

In conclusion, arc root behavior in an $\mathrm{Ar}-\mathrm{H}_{2}$ dc nontransferred plasma torch has been observed by a high-speed video camera. The shapes and motions of the attachments of the arc roots were strongly affected by the type of plasma gas used.

\section{REFERENCES}

[1] J. F. Coudert, V. Rat, and D. Rigot, "Influence of Helmholtz oscillations on arc voltage fluctuations in a dc plasma spraying torch," J. Phys. D, Appl. Phys., vol. 40, no. 23, pp. 7357-7366, Dec. 2007.

[2] E. Nogues, P. Fauchais, M. Vardelle, and P. Granger, "Relation between the arc-root fluctuations, the cold boundary layer thickness and the particle thermal treatment," J. Therm. Spray Technol., vol. 16, no. 5/6, pp. 919-926, Dec. 2007.

[3] A. K. Das, "Arc root dynamics in high power plasma torches-Evidence of chaotic behavior," Pramana-J. Phys., vol. 55, no. 5/6, pp. 873-886, Nov. 2000

[4] W. X. Pan, T. Li, X. Meng, X. Chen, and C. K. Wu, "Arc root attachment on the anode surface of arc plasma torch observed with a novel method," Chin. Phys. Lett., vol. 22, no. 11, pp. 2895-2898, Nov. 2005. 